\title{
Sıfır Değerlikli Mangan ve Ultrases ile Nitratın Kimyasal Denitrifikasyonu
}

\author{
Burcu İleri $^{1^{*}}$, Özge Terzioğlu ${ }^{1}$, Yasemin Çiçi ${ }^{1}$ \\ ${ }^{1}$ Çanakkale Onsekiz Mart Üniversitesi, Mühendislik Fakültesi, Çevre Mühendisliği Bölümü
}

20.02.2019 Geliş/Received, 24.05.2019 Kabul/Accepted

\section{Özet}

Bu çalışmada, sıfır değerlikli mangan $\left(\mathrm{Mn}^{0}\right)$ ve ultrases (US) prosesleri tekli ve birleşik $\left(\mathrm{US} / \mathrm{Mn}^{0}\right)$ kullanılarak, partikül dozu $(0.5,0.75,1,1.5$ ve $2 \mathrm{~g})$ ile reaksiyon süresinin $(0-60$ dk) nitrat $\left(\mathrm{NO}_{3}{ }^{-}\right)$giderimine etkisi araştırılmıştır. Ultrases prosesi tek başına uygulandığında nitrat $\left(\mathrm{NO}_{3}{ }^{-}\right)$giderimine etkisi az iken; $\mathrm{Mn}^{0}$ dozu arttıkça $\mathrm{NO}_{3}{ }^{-}$giderimi yükselmiştir. Birleşik $\mathrm{US} / \mathrm{Mn}^{0}$ uygulamasında ise ultrases etkisiyle $\mathrm{Mn}^{0}$ partiküllerinin kimyasal denitrifikasyon kapasitesini arttırdığ giderimi gerçekleşirken, aynı deneysel şartlarda ultrasonik mekanik kuvvet etkisi ile $30 \mathrm{dk}$ içerisinde $\% 95$ civarında bir $\mathrm{NO}_{3}{ }^{-}$giderimi elde edilmiştir. US/Mn ${ }^{0}$ ile nitratın indirgenmesi sonucu nitrit $\left(\mathrm{NO}_{2}^{-}\right)$ve amonyum $\left(\mathrm{NH}_{4}{ }^{+}\right)$indirgenme bileşikleri az miktarda oluşurken, azot gazına $\left(\mathrm{N}_{2}\right)$ dönüşüm oranının arttığı tespit edilmiştir.

Anahtar Kelimeler: kimyasal denitrifikasyon, nitrat, sıfır değerlikli mangan, ultrases

\section{Nitrate Chemical Denitrification with Zero-Valent Manganese and Ultrasound}

\begin{abstract}
In this study, the effect of particle dose $(0.5,0.75,1,1.5$ and $2 \mathrm{~g})$ and duration $(0-60 \mathrm{~min})$ using zero-valent manganese $\left(\mathrm{Mn}^{0}\right)$ and ultrasound (US) processes alone and combined $\left(\mathrm{US} / \mathrm{Mn}^{0}\right)$ on nitrate $\left(\mathrm{NO}_{3}{ }^{-}\right)$removal were investigated. When the ultrasound process was applied alone, there was little effect on removal of $\mathrm{NO}_{3}^{-}$. Also, as the $\mathrm{Mn}^{0}$ dose increased the $\mathrm{NO}_{3}{ }^{-}$removal increased as well. It was determined that the effect of the combined US/Mn application increases the chemical denitrification capacity of $\mathrm{Mn}^{0}$ particles. With only $\mathrm{Mn}^{0}$ at the end of 60 min, only $70 \% \mathrm{NO}_{3}{ }^{-}$removal occurred, while with the ultrasonic mechanical force effect in the same experimental conditions $95 \% \mathrm{NO}_{3}{ }^{-}$removal was obtained within 30 min. The reduction of $\mathrm{NO}_{3}{ }^{-}$with $\mathrm{US} / \mathrm{Mn}^{0}$ led to formation of small amounts of nitrite $\left(\mathrm{NO}_{2}{ }^{-}\right)$ and ammonium $\left(\mathrm{NH}_{4}{ }^{+}\right)$reduction compounds, with an increase in transformation rate to nitrogen gas $\left(\mathrm{N}_{2}\right)$ identified.
\end{abstract}

Keywords: chemical denitrification, nitrate, zero-valent manganese, ultrasound

\footnotetext{
*Sorumlu Yazar (Corresponding Author): Burcu İleri

(e-posta: burcuileri@comu.edu.tr)

Bu makale TÜBİTAK 2209-A Üniversite Öğrencileri Araştırma Projeleri Destekleme Programı

1919B011602884 numaralı projesi tarafından desteklenmiştir.
} 


\section{Giriş}

Azotlu bileşikler katı atık sızıntı sularından, tarımsal faaliyetlerden, endüstriyel ve atıksu tesislerden yerüstü ve yeraltı sularına ulaşmaktadır. Özellikle azotlu gübre ve tarım ilaçlarından kaynaklı toksik kirleticiler içme ve sulama sularının kirlenmesinde önemli bir paya sahiptir (Agrawal ve ark., 1999; Almasri ve Kaluarachchi, 2004; Doğanlar, 2006; Polat ve ark., 2007; Almasri, 2007; Harter, 2009; Archna, 2012). Azotlu gübreler toprakta yeterli miktarda oksijenin bulunmas durumunda amonyum $\left(\mathrm{NH}_{4}{ }^{+}\right)$ve amonyak $\left(\mathrm{NH}_{3}\right)$ kolayca nitrata $\left(\mathrm{NO}_{3}{ }^{-}\right)$parçalanmaktadır (Almasri ve Kaluarachchi, 2004; Doğanlar, 2006; Almasri, 2007). Toprakta biriken $\mathrm{NO}_{3}{ }^{-}$yağış suları ile birlikte yüzey ve yeraltı sularına taşınmaktadır. Yeralt1 suyundaki azotun genel formu $\mathrm{NO}_{3}{ }^{-}$olsa da, çözünmüş azot, $\mathrm{NH}_{4}{ }^{+}, \mathrm{NH}_{3}, \mathrm{NO}_{2}{ }^{-}, \mathrm{N}_{2}$, $\mathrm{N}_{2} \mathrm{O}$ ve organik azot şeklinde de bulunmaktadır (Doğanlar, 2006; Polat ve ark., 2007; Almasri, 2007; Harter, 2009; Archna, 2012). İçme amaçlı kullanılan sularda $\mathrm{NO}_{3}{ }^{-}$ konsantrasyonu maksimum $50 \mathrm{mg} / \mathrm{l}$ değerinde olması gerekmektedir (İTASHK, 2005). İçme sularındaki $\mathrm{NO}_{3}{ }^{-}$konsantrasyonun sınır değeri aşması durumunda 6 aylıktan küçük bebeklerde mavi bebek hastalığına sebep olmaktadır. İnsan sağlığını etkilediğinden içme suyu amaçlı kullanılacak olan yüzeysel ve yeraltı suyundan nitratın giderimi önemlidir. $\mathrm{NO}_{3}{ }^{-}$ gideriminde, biyolojik nitrifikasyon, distilasyon, kimyasal indirgeme, iyon değişimi, elektrodiyaliz ve ters osmoz gibi yöntemler kullanılmaktadır (Keeney ve Olson, 1986; Kapoor ve Viraraghavan, 1997; Mahamuni ve Adewuyi, 2009; Oğuz, 2015). Son zamanlarda $\mathrm{NO}_{3}{ }^{-}$ indirgemesinde dikkat çeken proseslerden birisi de kimyasal denitrifikasyondur. Kimyasal denitrifikasyon yöntemi ile sıfır değerlikli demir $\left(\mathrm{Fe}^{0}\right)$, sıfır değerlikli alüminyum $\left(\mathrm{Al}^{0}\right)$, sıfır değerlikli magnezyum $\left(\mathrm{Mg}^{0}\right)$, sıfır değerlikli çinko $\left(\mathrm{Zn}^{0}\right)$, sıfır değerlikli mangan $\left(\mathrm{Mn}^{0}\right)$ gibi elementler kullanılarak, $\mathrm{NO}_{3}^{-}$bileşiği $\mathrm{NO}_{2}^{-}, \mathrm{NH}_{4}{ }^{+}$veya $\mathrm{N}_{2}$ gazına indirgenmekte, sifır değerlikli metal partikülleri $\left(\mathrm{M}^{0}\right)+2$ veya daha yukarı değerlikli katyonlara yükseltgenmektedir (Hu ve ark., 2001; Luk ve Au-Yeung, 2002; Choe ve ark., 2004; Kumar ve Chakraborty, 2006; Patel ve Suresh, 2006; Bokare ve Cho, 2008; Hwang ve ark., 2011; Ramavandi ve ark., 2011; Crane ve Scott, 2012; Suziki ve ark., 2012; İleri ve ark., 2015a; İleri ve ark., 2015b; Fargas, 2017; Chiu ve ark., 2019). $\mathrm{NO}_{3}{ }^{-}$indirgemesinde suyun pH değeri ve sıfır değerlikli metal partiküllerinin elektrokimyasal potansiyelinin $\left(\mathrm{E}^{0}\right)$ etkili olduğu çalışmalarda vurgulanmıştır. Suziki ve ark. (2012) ile Hwang ve ark. (2011) tarafından nitratın indirgemesinde $\mathrm{Fe}^{0}$ partikülü kullanılmış ve $\mathrm{NO}_{3}{ }^{-}$giderim veriminin alkali şartlarda daha yüksek olduğu tespit edilmiştir. Sıfır değerlikli magnezyum $\left(\mathrm{Mg}^{0}\right)$ ile yapılan çalışmada ise, $\mathrm{pH}$ değeri asidik şartlarda sabit tutulduğunda magnezyum yüzey aktivitesi arttı̆̆ından $\mathrm{NO}_{3}{ }^{-}$gideriminin arttığ indirgenme potansiyelinin azaldığı rapor edilmiştir (Kumar ve Chakraborty, 2006; İleri ve ark., 2015a; İleri ve ark., 2015b).

Literatürdeki çalışmalar incelendiğinde nitratın indirgemesinde $\mathrm{Fe}^{0}$ kullanımının oldukça fazla olduğu görülmektedir (Zhang ve ark., 2010; Hwang ve ark., 2011; Suziki ve ark., 2012). $\mathrm{Fe}^{0}$ metali reaksiyon sonunda $\mathrm{Fe}^{+2}$ olarak çökeldiğinden suda renk oluşmasına sebep olmaktadır. $\mathrm{Bu}$ sebeple nitratın indirgemesinde yüzey elektrokimyasal potansiyeli $\left(\mathrm{E}^{0}\right)$ yüksek olan diğer sıfır değerlikli metallerin kullanımı da yaygınlaştırılmadır. Sıfır değerlikli alüminyum $\left(\mathrm{E}^{0}=\right.$ $1.66 \mathrm{~V})$ ve magnezyum $\left(\mathrm{E}^{0}=2.37 \mathrm{~V}\right)$ metalinden sonra sıfır değerlikli mangan $\left(\mathrm{Mn}^{0}\right)\left(\mathrm{E}^{0}=\right.$ $1.18 \mathrm{~V}$ ) en yüksek $\mathrm{E}^{0}$ sahip metal partikülüdür (Zhu ve Getting, 2012; Dada ve ark., 2017). $\mathrm{Mn}^{0}$ ile nitratın indirgemesi konusunda literatürde sınırlı sayıda çalışma bulunmasına rağmen, yürütülen çalışmalar çoğunlukla arsenik, bakır gibi metallerin giderimi üzerindedir (Dada ve ark., 2017; Panda ve ark., 2019). Sifır değerlikli manganın elektrokimyasal potansiyeli $\mathrm{Fe}^{0^{\prime}}$ a $\left(\mathrm{E}^{0}=\right.$ $0.44 \mathrm{~V})$ göre daha yüksek olduğundan nitratın kimyasal denitrifikasyon işlemi daha hızlı gerçekleşmektedir. Azot oksitlerin kimyasal denitrifikasyonu için $\mathrm{Mn}^{0}$ indirgeyicisi $\mathrm{Mn}^{+2}$ ye 
yükseltgenmekte ve $\mathrm{N}_{2}$ (Eşitlik 2), $\mathrm{NO}_{2}{ }^{-}$(Eşitlik 3) veya $\mathrm{NH}_{4}{ }^{+}$(Eşitlik 4) gibi kimyasal denitrifikasyon ürünleri oluşmaktadır.

$$
\begin{aligned}
& \mathrm{Mn}_{(\mathrm{k})}^{0} \rightarrow \mathrm{Mn}^{+2}(\mathrm{~s})+2 \mathrm{e}^{-} \quad \mathrm{E}^{0}=1.18 \mathrm{~V} \\
& 2 \mathrm{NO}_{3}{ }^{-}+5 \mathrm{Mn}^{0}+6 \mathrm{H}_{2} \mathrm{O} \rightarrow 5 \mathrm{Mn}^{+2}+\mathrm{N}_{2}+12 \mathrm{OH}^{-} \\
& \mathrm{NO}_{3}{ }^{-}+\mathrm{Mn}^{0}+2 \mathrm{H}^{+} \rightarrow \mathrm{Mn}^{+2}+\mathrm{NO}_{2}^{-}+\mathrm{H}_{2} \mathrm{O} \\
& \mathrm{NO}_{3}{ }^{-}+4 \mathrm{Mn}^{0}+10 \mathrm{H}^{+} \rightarrow 4 \mathrm{Mn}^{+2}+\mathrm{NH}_{4}^{+}+3 \mathrm{H}_{2} \mathrm{O}
\end{aligned}
$$

Nitratın indirgemesi sırasında gerçekleşen kimyasal reaksiyonlar partikül yüzeyinde adsorpsiyon, indirgenme veya desorpsiyon mekanizmaları ile sağlanmaktadır. Reaksiyon sonucunda partikül yüzeyi oksit bir tabaka ile kaplanarak indirgeme kapasitesi azalmaktadır. Kimyasal indirgeme kapasitesini yükseltmek ve partikül yüzey aktivasyonunu sağlamak amaciyla son zamanlarda ultrases prosesi tercih edilmektedir. Ultrases kavitasyon prensibine göre su içinde oluşan kabarcıkların yüksek sıcaklık ve basınç altında patlaması sonucu fiziksel ve kimyasal etkisi ile oluşan $\cdot \mathrm{H}, \cdot \mathrm{OH}$ ve $\cdot \mathrm{OH}_{2}$ radikaller sayesinde partikül yüzey aktivasyonu sağlanmaktadır (Eşitlik 5-7) (Adewuyi, 2001; Mason ve Peters, 2001; Mason ve Peters, 2002; Morais ve ark., 2002; Geiger ve ark., 2002; Liang ve ark., 2008).

$$
\begin{aligned}
& \left.\left.\left.\mathrm{H}_{2} \mathrm{O}+\right)\right)\right) \rightarrow \cdot \mathrm{OH}+\cdot \mathrm{H} \\
& \bullet \mathrm{H}+\mathrm{O}_{2} \rightarrow \mathrm{HO}_{2} \bullet \\
& \cdot \mathrm{OH}+\cdot \cdot \mathrm{OH} \rightarrow \mathrm{H}_{2} \mathrm{O}_{2}
\end{aligned}
$$

Su içinde ne kadar fazla radikal üretim gerçekleşirse partikül yüzeyi o kadar fazla aktive edilerek daha fazla yüzey alanı elde edilmektedir. Azot oksitlerin reaksiyon sonunda oluşturduğu pasif film, partikül yüzey aktivitesini azaltarak adsorpsiyon kapasitesinin yavaşlamasına sebep olmaktadır. Farklı frekanslarda çalışan ultrases prosesi sayesinde partikül yüzeyi aktive edilmekte ve arıtma veriminin artması sağlanmaktadır (Mason ve Peters, 2001; İleri ve ark., 2015a). Ultrases destekli yürütülen çalışmalarda daha çok $\mathrm{Fe}^{0}, \mathrm{Al}^{0}$, $\mathrm{Mg}^{0}$ partikülleri kullanılarak $\mathrm{NO}_{3}{ }^{-}$giderimi çalışılmıştır. $\mathrm{NO}_{3}{ }^{-}$indirgemesinde birleşik US/Fe ${ }^{0}$ ve $\mathrm{US} / \mathrm{Mg}^{0}$ ile yapılan çalışmalarda, ultrases prosesinin oksit filmin önlenmesi veya yıkımında yardımcı olduğu vurgulanmıştır (Morais ve ark., 2002; Liang ve ark., 2008; Tsai ve ark., 2009; İleri ve ark., 2015a). İleri ve ark. (2015) tarafından yapılan çalışmada, nitratın kimyasal denitrifikasyonunda birleşik US/ $\mathrm{Mg}^{0}$ prosesi denenmiş ve ultrases mekanik kuvvet etkisi ile $\mathrm{Mg}^{0}$ partikül yüzey alanı arttığından $\mathrm{NO}_{3}^{-}$gideriminde $\mathrm{Mg}^{0}$ doz ve reaksiyon süresinin yarıya indirildiği tespit edilmiştir.

$\mathrm{Bu}$ çalışmada, nitratın indirgenmesinde sıfır değerlikli mangan $\left(\mathrm{Mn}^{0}\right)$ partikülü ve ultrases prosesinin (US) tekli ve birleşik (US/Mn ${ }^{0}$ ) uygulamaları kullanılmış ve partikül dozu ile reaksiyon süresi dikkate alınarak deneysel çalışmalar yürütülmüştür. Optimum işletim şartlarında nitrat içeriği yüksek yeraltı suyundan nitratın indirgenmesinde $\mathrm{Mn}^{0}$ ve US/Mn proseslerinin etkisi araştırılmıştır. Ultrases etkisiyle $\mathrm{Mn}^{0}$ yüzeyinde oluşan kimyasal değişiklikler taramalı elektron mikroskobu (SEM/EDS), X-ışını kırınımı (XRD) ve partikül boyut analizleri ile tespit edilmiştir. Ultrases destekli $\mathrm{Mn}^{0}$ partikülü kullanılarak nitratın arıtımı üzerine çalışmalar literatürde sınırlı olduğundan, bu çalışma ile elde edilen sonuçların, bundan sonra yapılacak diğer bilimsel çalışmalar için bir referans olması hedeflenmektedir. 


\section{Materyal ve Yöntem}

Bu çalışmada, kesikli reaktör sisteminde $\mathrm{Mn}^{0}$ partikülü ile US prosesi kullanılarak nitratın indirgemesi kapsamlı bir şekilde irdelenmiştir. Sentetik nitrat çözeltisi potasyum nitrat $\left(\mathrm{KNO}_{3}\right)\left(\right.$ Merck) kimyasalı kullanılarak hazırlanmıştır. Nitrat içerikli çözeltiler $\left(50 \mathrm{mg} \mathrm{NO}_{3}{ }^{-}\right.$ $\mathrm{N} / \mathrm{l}$ ) öncelikle sadece $\mathrm{Mn}^{0}$ ile arıtma işlemine tabi tutulmuştur. Daha sonra $40 \mathrm{kHz}$ frekanslı ultrases cihazı ile birleşik US/ $\mathrm{Mn}^{0}$ prosesi uygulanarak nitratın indirgenmesine olan etkisi araştırılmış ve oluşan kimyasal denitrifikasyon ürünleri $\left(\mathrm{NO}_{2}{ }^{-}, \mathrm{NH}_{4}{ }^{+}\right.$veya $\left.\mathrm{N}_{2}\right)$ detaylı bir şekilde analiz edilmiştir. $\mathrm{pH}$ değerini nötr seviyede tutmak amaciyla 3-(N-morpholino) propansulfonik asit (MOPs) kimyasalı kullanılmıştır.

\subsection{Yeraltı Suyu Örneğinin Karakterizyonu}

Yeraltı suyu örneği Çanakkale İli’nde tarımsal faaliyetin yoğun olduğu Biga ovasından temin edilmiştir. $15 \mathrm{~m}$ derinlikte olan sondaj kuyusundan alınan yeraltı suyu örneğinin karakterizasyonu Çizelge 2.1' de verilmiştir. Nitrat azotu $\left(\mathrm{NO}_{3}^{-}-\mathrm{N}\right)$ ve demir $\left(\mathrm{Fe}^{+2}\right)$ konsantrasyonu Hach Lange DR5000 model UV-VIS spektrofotometre cihazı yardımıyla ölçülmüştür. pH değeri WTW marka pH probu ile, bulanıklık değeri ise Hach Lange model cihaz yardımıyla ölçülmüştür. Toplam sertlik, klorür, sülfat ve alkalinite analizleri standart metoda göre belirlenmiştir (APHA, 2005).

Çizelge 2.1. Yeraltı suyu karakterizasyonu

\begin{tabular}{|l|c|c|}
\hline \multicolumn{1}{|c|}{ Parametre } & Birimi & Konsantrasyon $(\mathrm{mg} / \mathrm{l})$ \\
\hline $\mathrm{pH}$ & - & 7.54 \\
\hline Bulanıklık & NTU & 1 \\
\hline Nitrat azotu $\left(\mathrm{NO}_{3}{ }^{-}-\mathrm{N}\right)$ & $\mathrm{mg} / \mathrm{l}$ & 42 \\
\hline Toplam Sertlik & $\mathrm{mg} / \mathrm{l}$ & 280 \\
\hline Klorür $\left(\mathrm{Cl}^{-}\right)$ & $\mathrm{mg} / \mathrm{l}$ & 75 \\
\hline Sülfat $\left(\mathrm{SO}_{4}^{-2}\right)$ & $\mathrm{mg} / \mathrm{l}$ & 220 \\
\hline Alkalinite $\left(\mathrm{HCO}_{3}{ }^{-}\right)$ & $\mathrm{mg} / \mathrm{l}$ & 55 \\
\hline Demir $\left(\mathrm{Fe}^{+2}\right)$ & $\mathrm{mg} / \mathrm{l}$ & 0.6 \\
\hline
\end{tabular}

\subsection{Sıfır Değerlikli Mangan $\left(\mathrm{Mn}^{0}\right)$ İle Nitratın Kimyasal Denitrifikasyonu}

Deneyler kesikli reaktör düzeneğinde sabit hacim $(200 \mathrm{ml})$ ve sicaklıkda $\left(20{ }^{\circ} \mathrm{C}\right)$ gerçekleştirilmiştir. Analitik saflı̆̆ $\% 99$ (Sigma) ve yoğunluğu $7.21 \mathrm{~g} / \mathrm{cm}^{3}$ olan sıfır değerlikli mangan $\left(\mathrm{Mn}^{0}\right)$ partikülü kullanılmıştır. $\mathrm{Mn}^{0}$ partikülünün oksitlenmesini önlemek için sudaki çözünmüş oksijen değeri argon gazıyla kontrol edilmiştir. Deneyden önce çözeltiye 1 l/dk akış hızında argon gazı verilerek oksijen değeri minimum seviyeye düşürülmüştür. Deneyde sentetik nitrat çözeltisi ile yeraltı suyu örnekleri kullanılmış ve $\mathrm{Mn}^{0}$ dozu $0.5,0.75,1,1.5$ ve $2 \mathrm{~g}$ olarak seçilmiştir. Örnekler orbital çalkalayıcı (BioSan) yardımıyla homojen karışımları sağlanmıştır. Bir saat süresince 10'ar dakika aralıklarla reaktörden örnek çekilmiş ve $0.45 \mu \mathrm{m}$ çapında filtreden süzülmüştür. Filtre edilen örnek için nitrat azotu $\left(\mathrm{NO}_{3}{ }^{-} \mathrm{N}\right)$, nitrit azotu $\left(\mathrm{NO}_{2}{ }^{-} \mathrm{N}\right)$ ve amonyum azotu $\left(\mathrm{NH}_{4}{ }^{+}-\mathrm{N}\right)$ konsantrasyonlar1 analiz edilmiş ve elde edilen sonuçlara göre optimum partikül doz ve reaksiyon süresi tespit edilmiştir. 


\subsection{Birleşik US/Mn ${ }^{0}$ Prosesi İle Nitratın Kimyasal Denitrifikasyonu}

Birleşik ultrases ve sıfır değerlikli mangan ( $\left.\mathrm{Mn}^{0} / \mathrm{US}\right)$ ile yapılan deneylerde $150 \mathrm{~W}$ gücünde ve $40 \mathrm{kHz}$ frekansında ultrasonik banyo (Isolab) cihazı kullanılmıştır (Şekil 2.1). Birleşik $\mathrm{US} / \mathrm{Mn}^{0}$ ile partikül yüzey alanının arttırılması ve çap aralığının azaltılması amaçlanmıştır. Ultrases uygulamalarından kaynaklanan ısı artışlarını dengelemek için sıcaklık sürekli kontrol edilmiştir. Ultrasonik banyo ile yürütülen deneylerde cihazın birim hacim başına suya geçen güç yoğunluğunu (W/ml) belirlemek amacıyla kalorimetrik test kullanılmıştır (İleri, 2016). Belli zaman aralıklarında suyun sıcaklık değeri ölçülmüş ve eşitlik 8 kullanılarak güç değeri $35 \mathrm{~W} / \mathrm{ml}$ olarak hesaplanmıştır.

$\mathrm{P}_{\mathrm{cal}}=\frac{\Delta T}{\Delta t} \mathrm{C}_{\mathrm{p}} * \mathrm{M}_{\mathrm{w}}$

Eşitlikte;

Cp: Suyun 1s1 kapasitesi, $\mathrm{Cp}=4.2 \mathrm{~J} / \mathrm{g} * \mathrm{~K}$

Mw: Reaktördeki su kütlesi [g]

$\Delta \mathrm{T}$ : Herhangi bir i anındaki sıcaklık ile ile j anındaki sıcaklık fark1

$\Delta \mathrm{t}$ : Herhangi bir $\mathrm{i}$ anı ile $\mathrm{j}$ anı arasındaki süre farkı

$\frac{\Delta T}{\Delta t}=$ Grafik eğimi

Deneyde sentetik nitrat çözeltisi ve yeraltı suyu örneği kullanılmıştır. $\mathrm{Mn}^{0}$ partikülünün oksitlenmesini önlemek amacıyla suya argon gazı verilmiştir. Birleşik US/Mn ${ }^{0}$ prosesi için $0.5,0.75,1,1.5$ ve $2 \mathrm{~g} \mathrm{Mn}^{0}$ dozları seçilmiştir. Deney süresince 10 'ar dakika aralıklarla reaktörden örnek alınmış ve $0.45 \mu \mathrm{m}$ çapındaki filtreden süzülmüştür. Filtre edilen örnek için $\mathrm{NO}_{3}{ }^{-}-\mathrm{N}, \mathrm{NO}_{2}{ }^{-} \mathrm{N}$ ve $\mathrm{NH}_{4}{ }^{+}-\mathrm{N}$ konsantrasyonları analiz edilmiş ve elde edilen sonuçlara göre optimum partikül doz ve reaksiyon süresi tespit edilmiştir.

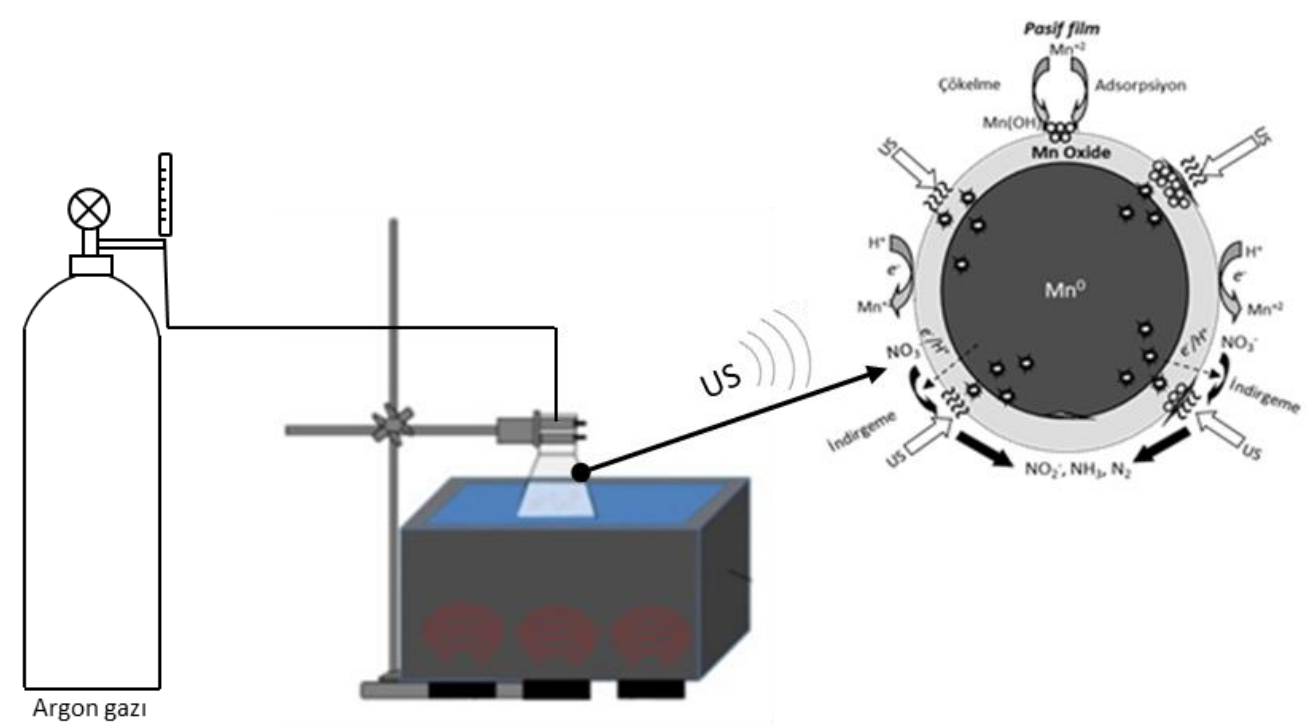

Şekil 2.1. US/Mn ${ }^{0}$ prosesi ile nitrat indirgeme deney düzeneği 


\subsection{Analitik Prosedür}

$\mathrm{NO}_{3}{ }^{-}-\mathrm{N}, \mathrm{NO}_{2}{ }^{-}-\mathrm{N}$ ve $\mathrm{NH}_{4}{ }^{+}-\mathrm{N}$ konsantrasyonları standart metoda göre test edilmiş (APHA, 2005) ve Hach Lange DR5000 model UV-VIS spektrofotometre cihazı kullanılarak ölçülmüştür. Hazırlanan kalibrasyon eğrisine göre absorbans değerlerine karşılık gelen azot türünün çözeltide kalan konsantrasyonları hesaplanmıştır. Azot gazı $\left(\mathrm{N}_{2}\right)$ konsantrasyonu ise aşağıda gösterildiği gibi toplam azot kütlesi dengesinden hesaplanmıştır (İleri ve ark., 2015b):

$$
\mathrm{N}_{2(\mathrm{t})}=\mathrm{NO}_{3}-\mathrm{N}_{(\mathrm{o})}-\left[\mathrm{NO}_{3}-\mathrm{N}_{(\mathrm{t})}+\mathrm{NO}_{2}-\mathrm{N}_{(\mathrm{t})}+\mathrm{NH}_{4}-\mathrm{N}_{(\mathrm{t})}\right]
$$

$\mathrm{N}_{2(\mathrm{t})}$ : Her hangi bir $t$ anında oluşan azot gazı konsantrasyonu (mg/l)

$\mathrm{NO}_{3}-\mathrm{N}_{(\mathrm{o})}$ : Başlangıçta $(t=0)$ sudaki nitrat-azotu konsantrasyonu $(\mathrm{mg} / \mathrm{l})$

$\mathrm{NO}_{3}-\mathrm{N}_{(\mathrm{t})}$ : Her hangi bir $t$ anında kalan nitrat-azotu konsantrasyonu $(\mathrm{mg} / \mathrm{l})$

$\mathrm{NO}_{2}-\mathrm{N}_{(\mathrm{t})}$ : Herhangi bir $t$ anında oluşan nitrit-azotu konsantrasyonu (mg/l)

$\mathrm{NH}_{4}-\mathrm{N}_{(\mathrm{t})}$ : Her hangi bir $t$ anında oluşan amonyum-azotu konsantrasyonu (mg/l)

\subsection{Sıfır Değerlikli Mangan (Mnº) Partikülünün Yüzey Analizi}

$\mathrm{Mn}^{0}$ ve US/Mn ${ }^{0}$ arıtma işlemleri sonucunda partikül yüzey özelliklerinde meydana gelen değişikliklerin tespiti ve nitrat kimyasal denitrifikasyon hızına etkisinin belirlenmesi için fiziksel, kimyasal ve morfolojik analizleri yapılmıştır. Reaksiyon sonunda örnekler filtre edilmiş ve $\mathrm{Mn}^{0}$ partikülü $60-80^{\circ} \mathrm{C}^{\prime}$ de vakumlu etüvde (Nüve) 1 gün boyunca kurutulmuştur. $\mathrm{Mn}^{0}$ partikül boyutunun tespiti Malvern Mastersizer marka 2000 Hydro model cihaz ile, morfolojik içeriği SEM (JEOL SEM-7100) analizi ile tespit edilmiştir. Mineralojik bileşimi X-Ray difraction (XRD) (PANalytical Empyrean) kırınım yasasına göre 5-70 dalga boyu aralığında $3^{\circ} \mathrm{dk}^{-1}$ tarama hızında okuma yapılarak belirlenmiştir.

\section{Bulgular}

\subsection{Sıfır Değerlikli Mangan $\left(\mathrm{Mn}^{0}\right)$ Partikül Karakterizasyonu}

Sıfır değerlikli manganın $d_{10}, d_{50}$ ve $d_{90}$ partikül çap aralığı sırasıyla $4.96,14.1$ ve $54.7 \mu \mathrm{m}$ olduğu belirlenmiştir. SEM görüntüsüne göre, kullanılan $\mathrm{Mn}^{0}$ partikülünün homojen olmayan ve açık gri görünümde olduğu tespit edilmiştir (Şekil 3.1a). Yalnız $\mathrm{Mn}^{0}$ partikülü ile yapılan karıştırma deneyi sonunda partikül morfolojisinin fazla etkilenmediği görülmüştür (Şekil 3.1b). Birleşik US/ $\mathrm{Mn}^{0}$ uygulaması sonucu partiküllere ait SEM görüntüsü incelendiğinde US uygulamasına maruz bırakılmış $\mathrm{Mn}^{0}$ partiküllerin hem şekilsel hem de boyut olarak değişikliğe uğradıkları görülmektedir (Şekil 3.1c).
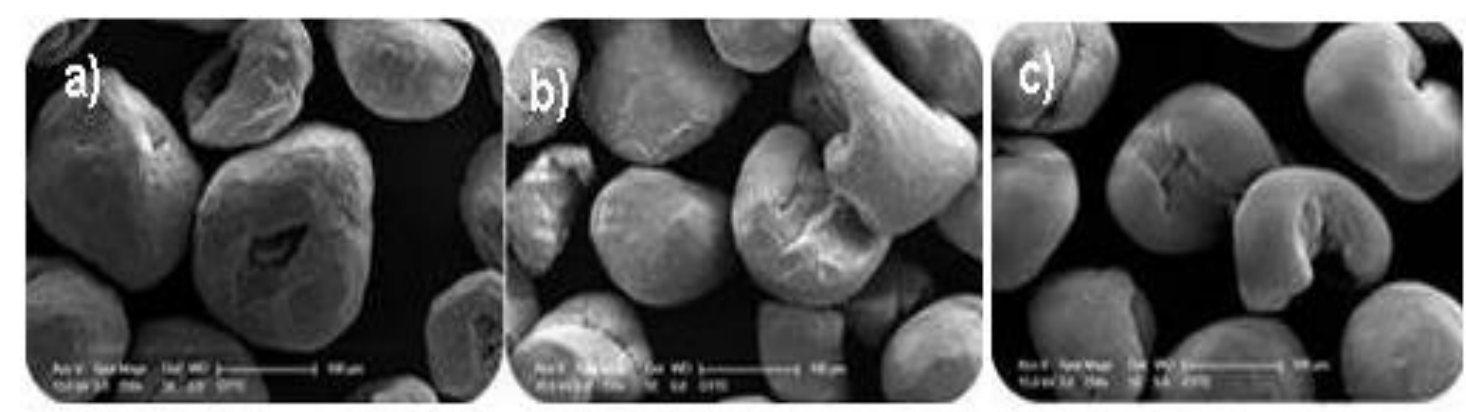

Şekil 3.1. Sifir değerlikli mangan partikülünün SEM görüntüsü (a) $\mathrm{Mn}^{0}$; b) $\mathrm{Mn}^{0} / 0 \mathrm{kHz}$; c) $\left.\mathrm{Mn}^{0} / 40 \mathrm{kHz}\right)$ 
XRD analizi kırınım yasasına göre, $\mathrm{Mn}^{0}$ partikülünün faz yapısında $\mathrm{Mn}, \mathrm{Mn}(\mathrm{OH})_{2}$ ve $\mathrm{Mn}_{2} \mathrm{O}_{3}$ bileşiklerine karşılık gelen pik şiddeti değerleri ölçülmüştür. Okunan her pik değerleri belli açılara karşılık gelen bileşiğe denk gelmektedir. Şekil 3.2'de verilen XRD grafiğinden, tüm piklerin mangan bileşiğine ait olduğu belirlenmiştir.

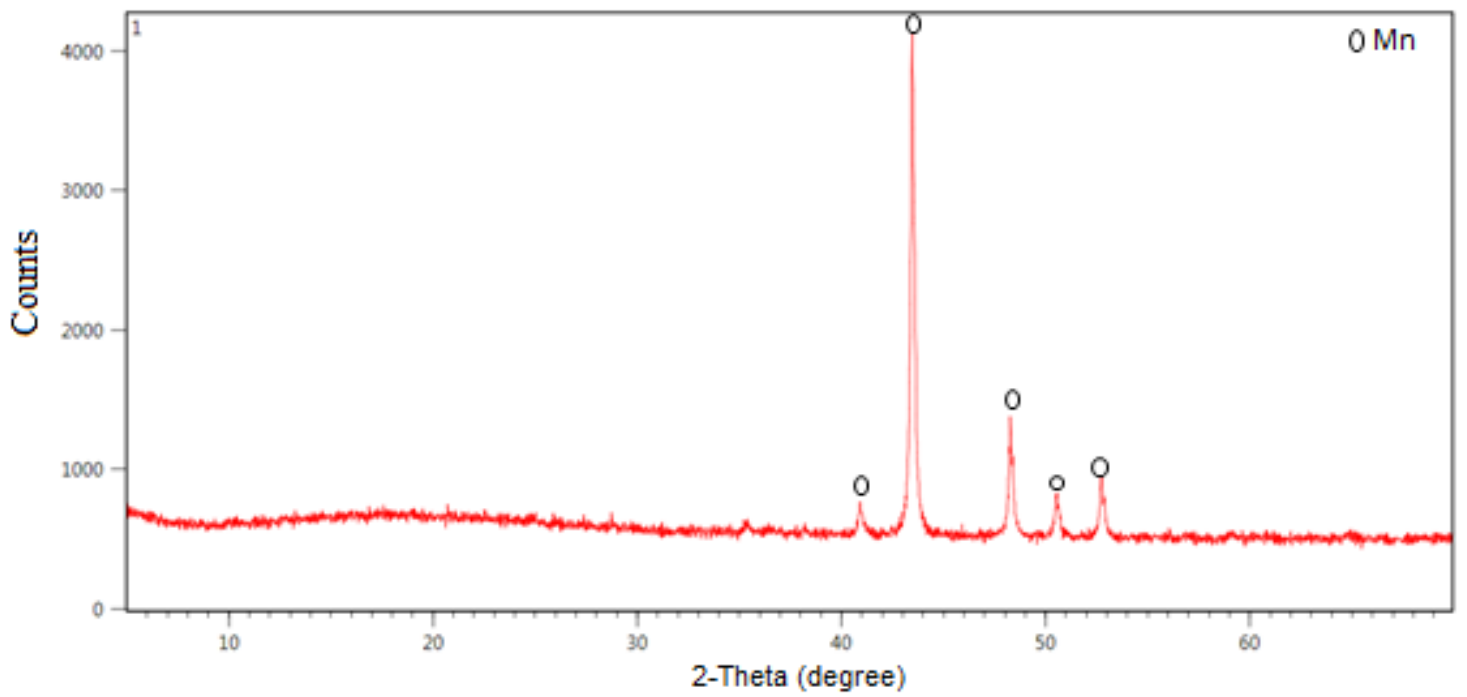

Şekil 3.2. Sifır değerlikli mangan partikülünün XRD analizi

\subsection{Sıfır Değerlikli Mangan $\left(\mathrm{Mn}^{0}\right)$ İle Nitratın Kimyasal Denitrifikasyonu}

Nitratın indirgenmesinde hem partikül dozu hem de reaksiyon süresi önemli bir parametredir. Yüksek dozda toplam partikül yüzey alanı daha fazla olduğundan nitratın indirgenmesi de daha hızlı gerçekleşmektedir. Elde edilen sonuçlara göre, $0.5 \mathrm{~g} \mathrm{Mn}^{0}$ dozunun $\mathrm{NO}_{3}{ }^{-} \mathrm{N}$ giderimine etkisi fazla gözlenmezken, $0.75 \mathrm{~g}$ ve $1 \mathrm{~g} \mathrm{Mn}{ }^{0}$ doz uygulamasında süre arttıkça $\mathrm{NO}_{3}{ }^{-}-\mathrm{N}$ giderimi artmış ve bu iki dozun nitrat indirgeme etkisi benzerlik göstermiştir. İnsani Tüketim Amaçlı Sular Hakkında Yönetmelik kriterlerine göre $\mathrm{NO}_{3}{ }^{-} \mathrm{N}$ değerinin maksimum $10 \mathrm{mg} / \mathrm{l}$ olmasına müsaade edilmektedir. Sıfır onda beş, 0.75 ve $1 \mathrm{~g} \mathrm{Mn}{ }^{0}$ dozu kullanıldığında reaksiyon sonunda müsaade edilen sınır değer sağlanamamıştır. Doz 1.5 g'a çıkarıldığında nitratın indirgemesi hızlanmış ve reaksiyon sonuna kadar $\mathrm{NO}_{3}{ }^{-} \mathrm{-}$ konsantrasyonu azalmıştır. Bir onda beş g dozda 40.dk' da $\mathrm{NO}_{3}{ }^{-} \mathrm{N}$ konsantrasyonu sınır değerin altına düşerken; $2 \mathrm{~g}$ dozda ise 20. dk' da benzer sonuç elde edilmiştir (Şekil 3.3). Bu sonuçlardan da görüleceği üzere, nitratın kimyasal denitrifikasyonu $\mathrm{Mn}^{0}$ dozunun artmasıyla birlikte ciddi oranda artmaktadır. Örneğin dozun 0.5 g'dan 2 g'a arttırılması sonucunda toplam partikül yüzey alanı 4 katına çıktığından daha fazla reaktif yüzey alanı olması sebebiyle nitrat giderimi de daha yüksek elde edilmiştir.

Sıfır değerlikli metalik partiküller ile kirletici maddelerin arıtımı doğrudan veya dolaylı olarak partikül yüzeyinde gerçekleşmektedir. Partikül dozu arttıkça toplam aktif yüzey alanı artmakta ve buna bağlı olarak da daha fazla miktarda kirletici maddenin indirgenmesinin olduğu yapılan çalışmalar ile ortaya konmuştur (Choe ve ark., 2004; Suziki ve ark., 2012; İleri ve ark., 2015a). Bu tür uygulamalarda doz miktarındaki artışa bağlı olarak verimin iyileştirilmesi ancak belli bir doz değerine kadar etkili olabilmektedir. Su Kirliliği Kontrol Yönetmeliği’ne göre belirlenen sınır değerin sağlandığı doz miktarı aynı zamanda optimum doz olarak ifade edilmektedir. Partikül dozunun artmasıyla birlikte nitrat giderimi de artmış, $2 \mathrm{~g}$ doz uygulamasında $\mathrm{NO}_{3}{ }^{-} \mathrm{N}$ değeri sınır değer olan $10 \mathrm{mg} / \mathrm{l}$ altına düşürülmüştür. $\mathrm{Bu}$ 
sonuçlara göre yalnız $\mathrm{Mn}^{0}$ partikülleri ile yürütülen deneyler için reaksiyon süresinin kısa olması da göz önüne alındığında optimum $\mathrm{Mn}^{0}$ dozu 2 g olarak belirlenmiştir.

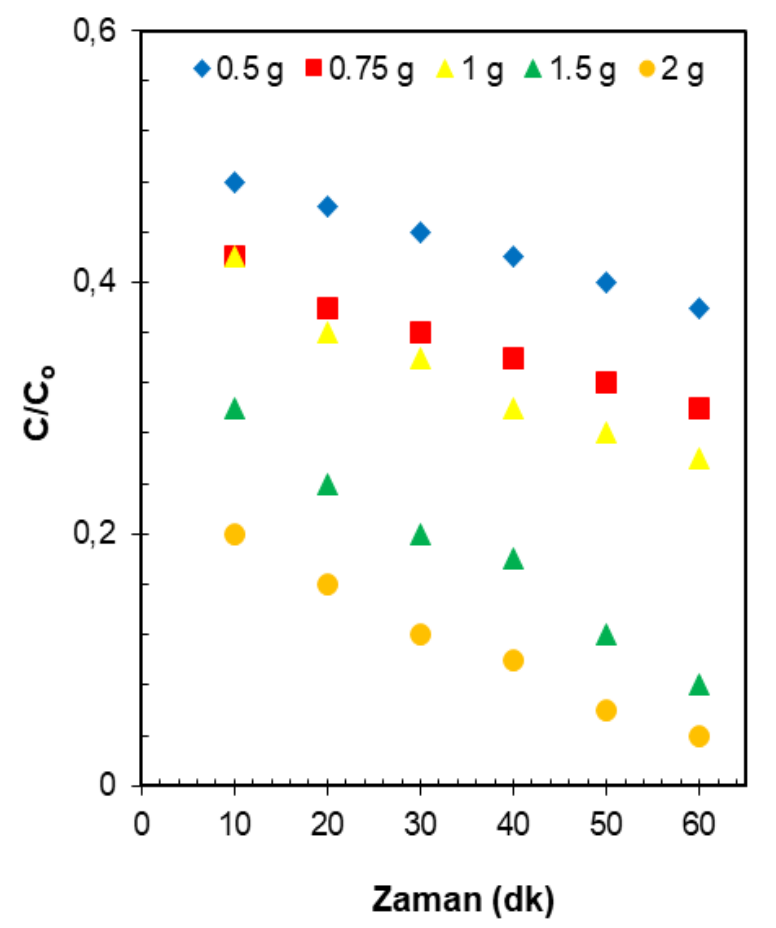

Şekil 3.3. Farklı dozlarda $\mathrm{Mn}^{0}$ ile nitratın kimyasal denitrifikasyonu (MOPs $=1 \mathrm{~g} ; \mathrm{C}_{0}=50 \mathrm{mg}$ $\left.\mathrm{NO}_{3}{ }^{-}-\mathrm{N} / \mathrm{l}\right)$

\subsection{Birleşik Ultrases Ve Sıfır Değerlikli Mangan $\left(\mathrm{Mn}^{0}\right)$ İle Nitratın Kimyasal Denitrifikasyonu}

Sıfır değerlikli mangan partikülleri $\left(\mathrm{Mn}^{0}\right) 40 \mathrm{kHz}$ frekanslı US ile aktive edilerek $\mathrm{NO}_{3}{ }^{-} \mathrm{N}$ gideriminin iyileştirilmesi amaçlanmıştır. Nitratın birleşik US/Mn ${ }^{0}$ ile gideriminde partikül dozu ve reaksiyon süresinin etkileri ayrıntılı bir şekilde araştırılmıştır. Farklı dozlarda $\mathrm{Mn}^{0}$ partikülleri ilave edilen $\mathrm{NO}_{3}{ }^{-} \mathrm{N}$ çözeltileri ultrasonik ortamda arıtılmış ve nitratın zamana bağlı giderimi Şekil 3.4'de gösterilmiştir. Ultrasonik ortamda $0.5,0.75,1,1.5$ ve $2 \mathrm{~g} \mathrm{Mn}^{0}$ partikülleri içeren çözeltilerin $60 \mathrm{dk}$ süre sonucunda $\mathrm{NO}_{3}{ }^{-} \mathrm{N}$ giderim oranları sırasıyla $\% 78$, $\% 96, \% 100, \% 100$ ve $\% 100$ olarak belirlenmiştir. Ultrases kavitasyon etkisinin giderimin artmasında oldukça etkili olduğu tespit edilmiştir. Ultrasesin meydana getirdiği kavitasyon ve mekanik kuvvet etkisi ile $\mathrm{Mn}^{0}$ partikülleri yüzeyinin hızla aktive olması sağlanmakta ve böylece daha fazla nitrat giderimi sağlanmaktadır. Sıfır onda beş g $\mathrm{Mn}^{0}$ dozunda sınır değer sağlanamazken; $0.75 \mathrm{~g} \mathrm{Mn}^{0}$ dozu için 30. $\mathrm{dk}^{\prime}$ da $\mathrm{NO}_{3}{ }^{-}-\mathrm{N}$ değeri $10 \mathrm{mg} / \mathrm{l}^{\prime}$ nin altına azalmıştır. Bir, 1.5 ve $2 \mathrm{~g} \mathrm{Mn}^{0}$ dozu kullanıldığında ise ilk $10 \mathrm{dk}$ sonunda sınır değer elde edilmiştir. $\mathrm{Bu}$ sonuçlara göre, birleşik US/Mn ${ }^{0}$ uygulamasında reaksiyon süresinin kısa olması istendiğinden optimum $\mathrm{Mn}^{0}$ dozu $1 \mathrm{~g}$ olarak seçilmiştir. Yalnız $\mathrm{Mn}^{0}$ partikülleri kullanıldığında $2 \mathrm{~g}$ dozda elde edilen sonuç, birleşik US/ $\mathrm{Mn}^{0}$ prosesi ile $1 \mathrm{~g} \mathrm{\textrm {Mn } ^ { 0 }}$ dozunda elde edilmiştir. Böylece ultrases kullanıldığında daha kısa sürede ve düşük dozda nitrat giderimi sağlanmıştır. Benzer sonuç İleri ve ark. (2015) tarafından yapılan çalışmada ortaya konmuş ve nitrat denitrifikasyonunda birleşik $\mathrm{US} / \mathrm{Mg}^{0}$ prosesi denenmiş ve ultrases mekanik kuvvet etkisinin partikül yüzey alanını arttırdığından nitrat gideriminde doz ve sürenin yarıya indirildiği tespit edilmiştir. 


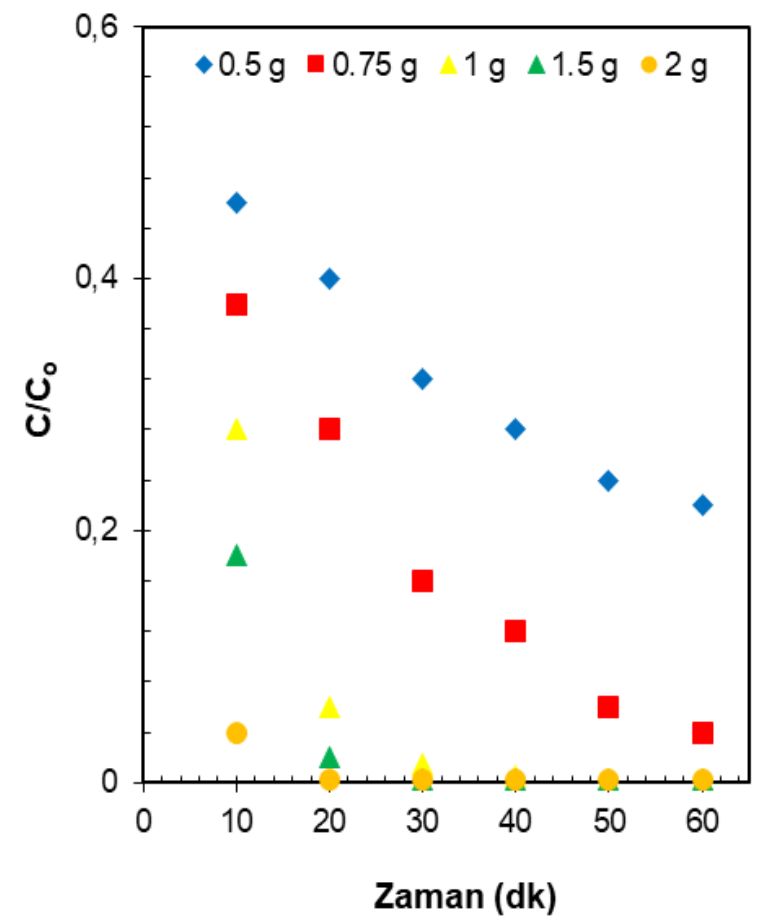

Şekil 3.4. Ultrasonik ortamda farklı dozlarda $\mathrm{Mn}^{0}$ ile nitratın kimyasal denitrifikasyonu (US = $\left.40 \mathrm{kHz} ; \mathrm{MOPs}=1 \mathrm{~g} ; \mathrm{C}_{0}=50 \mathrm{mg} \mathrm{NO}{ }_{3}^{-} \mathrm{-N} / \mathrm{l}\right)$

\subsection{Nitratın Kimyasal Denitrifikasyonu Sonucunda Oluşan Azot Bileşikleri}

Eşitlik 2-4' e göre nitratın kimyasal denitrifikasyonu sırasında $\mathrm{NO}_{2}^{-}, \mathrm{NH}_{4}{ }^{+}$ve $\mathrm{N}_{2}$ gibi yan ürünler açığa çıkmaktadır. Reaksiyon sırasında $\mathrm{NO}_{2}{ }^{-}$ve $\mathrm{NH}_{4}{ }^{+}$oluşabilmesi için proton $\left(\mathrm{H}^{+}\right)$ ihtiyacı olmaktadır. Özellikle $\mathrm{NH}_{4}{ }^{+}$bileşiğine indirgenebilmesi için $10 \mathrm{H}^{+}$protonuna ihtiyaç olduğu eşitlik 4'te görülmektedir. Bu sebeple reaksiyon alkali şartlarda gerçekleştiğinden nitratın $\mathrm{N}_{2}$ gazına indirgenmesinin daha yüksek olduğu görülmektedir. Yalnız $\mathrm{Mn}^{0}$ partikülü ve birleşik US/ $\mathrm{Mn}^{0}$ prosesi uygulamaları ile nitratın indirgemesi sonucunda oluşan azot formlarının $\left(\mathrm{NO}_{2}^{-}, \mathrm{NH}_{4}{ }^{+}\right.$ve $\left.\mathrm{N}_{2}\right)$ zamana bağlı konsantrasyon değerleri Şekil $3.5 \mathrm{a}, \mathrm{b}$ ' de sunulmuştur. Azot bileşiği olarak $\mathrm{NO}_{3}{ }^{-}, \mathrm{NO}_{2}{ }^{-}$ve $\mathrm{NH}_{4}{ }^{+}$konsantrasyonları analitik yöntemlerle, $\mathrm{N}_{2}$ konsantrasyonu ise toplam azot kütle dengesinden hesaplanmıştır (Eşitlik 9). Analiz sonuçlarına göre, $\mathrm{Mn}^{0}$ tek başına kullanıldı ğında $\% 74$ civarında $\mathrm{NO}_{3}^{-}-\mathrm{N}$ giderimi elde edilmiştir. Bir g $\mathrm{Mn}^{0}$ partikülü tek başına uygulandığında $60 \mathrm{dk}$ reaksiyon sonunda $\mathrm{NO}_{3}{ }^{-}-\mathrm{N}$ konsantrasyonu $50 \mathrm{mg} / \mathrm{l}$ 'den $13 \mathrm{mg} / \mathrm{l}^{\prime}$ ye ve giderilen nitratın $0.27 \mathrm{mg} / \mathrm{l}^{\prime}$ 'si $\mathrm{NO}_{2}{ }^{-} \mathrm{N}, 36.73$ $\mathrm{mg} / \mathrm{l}$ 'si $\mathrm{N}_{2}$ olarak kaydedilmiştir. $\mathrm{NH}_{4}{ }^{+}-\mathrm{N}$ oluşumu ise $0.1 \mathrm{mg} / \mathrm{l}$ 'nin altında ölçülmüştür (Şekil 3.5a). Birleşik US/Mn ${ }^{0}$ uygulaması sonucunda \%99 civarında $\mathrm{NO}_{3}{ }^{-}-\mathrm{N}$ giderimi elde edilmiş ve giderilen nitratın $0.33 \mathrm{mg} / \mathrm{l}$ 'si $\mathrm{NO}_{2}{ }^{-}-\mathrm{N}, 49.57 \mathrm{mg} / \mathrm{l}$ 'si $\mathrm{N}_{2}$ ve çok az miktarda $\mathrm{NH}_{4}{ }^{+}-\mathrm{N}$ olarak ölçülmüştür (Şekil 3.5b). Elde edilen sonuçlar göstermiştir ki, ultrasonik etki ile birlikte $\mathrm{NO}_{3}{ }^{-}$ kimyasal denitrifikasyon hızının arttığı ve denitrifikasyon ürünü olarak daha fazla $\mathrm{N}_{2}$ gazı oluşumu sağlanmıştır. $\mathrm{Bu}$ durum birleşik ultrases ve sıfır değerlikli mangan (US/ $\mathrm{Mn}^{0}$ ) uygulamalarında daha net bir şekilde görülmektedir (Şekil 3.5b). Nitratın kimyasal denitrifikasyonu sonucu azot gazına indirgendiği yapılan diğer çalışmalarda da ortaya konmuştur (Liang ve ark., 2008; İleri ve ark., 2015;) 

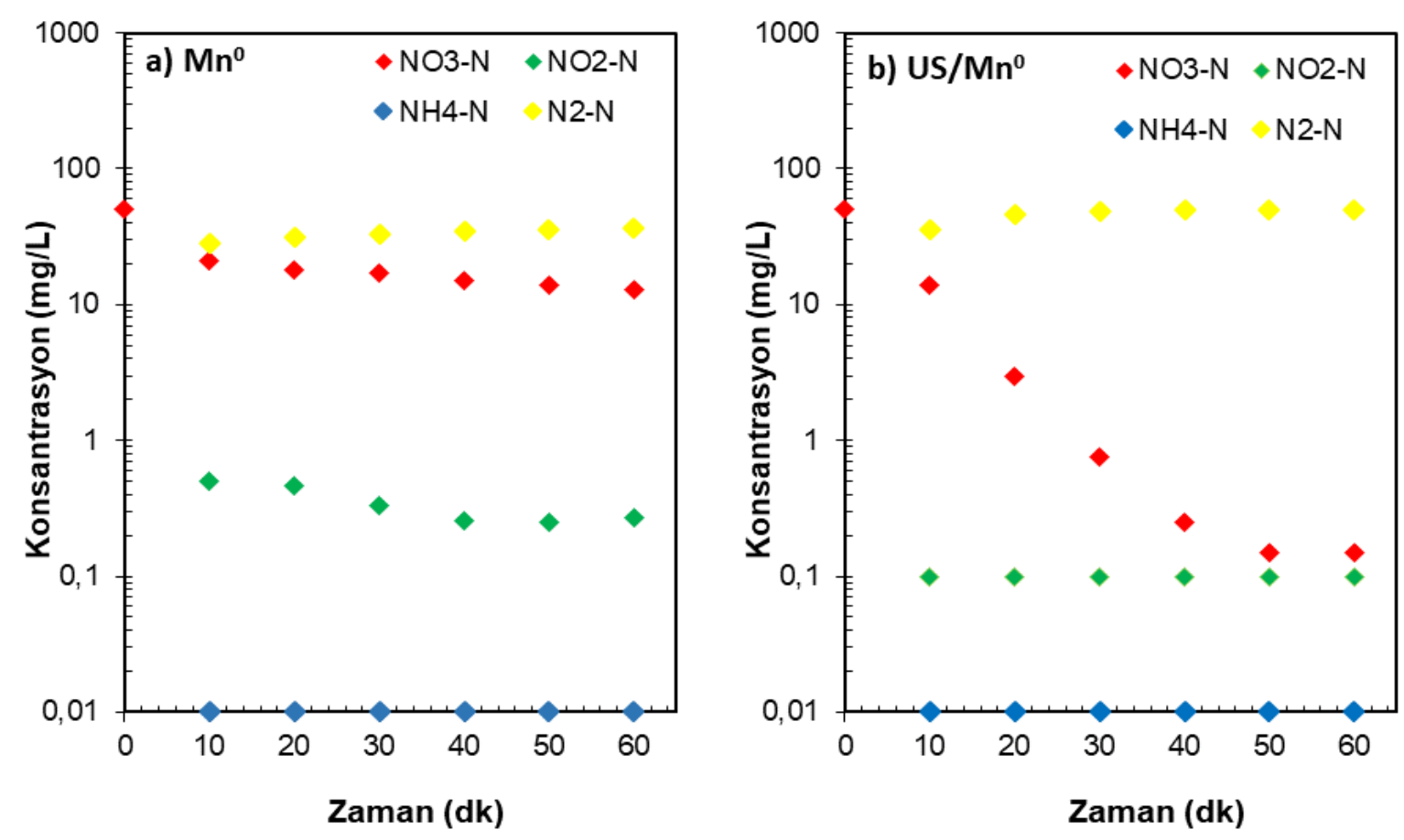

Şekil 3.5. $\mathrm{Mn}^{0}$ ve US/Mn ${ }^{0}$ ile nitrat indirgemesinin azotlu bileşik oluşumuna etkisi $\left(\mathrm{Mn}^{0}\right.$ dozu $\left.=1 \mathrm{~g} ; \mathrm{MOPs}=1 \mathrm{~g} ; \mathrm{C}_{0}=50 \mathrm{mg} \mathrm{NO}_{3}{ }^{-} \mathrm{N} / \mathrm{l}\right)$

\subsection{Ultrasonik Ortamda Sıfır Değerlikli Mangan İle Yeraltı Suyundan Nitrat Giderimi}

Sentetik nitrat çözeltilerinde $\mathrm{NO}_{3}{ }^{-} \mathrm{N}$ indirgemesi uygulandıktan sonra, $\mathrm{Mn}^{0}$ ve US/Mn prosesleri nitrat içeriği yüksek bir yeraltı suyunun arıtılmasında test edilmiştir. Bir ve $2 \mathrm{~g} \mathrm{Mn}^{0}$ dozunda yeraltı suyunda bulunan nitratın giderimi amacıyla yalnız $\mathrm{Mn}^{0}$ ve birleşik US/Mn uygulanarak arıtma proseslerinin etkisi karşılaştırılmıştır. İndirgeme sonucunda zamana bağlı kalan azot cinsinden nitrat ve oluşan nitrit, amonyum ve azot gazı miktarları Şekil 3.6a-d'de sunulmuştur. $\mathrm{Mn}^{0}$ dozu $1 \mathrm{~g}$ uygulandığında, yeraltı suyunda yaklaşı $\% 40$ civarında $\mathrm{NO}_{3}{ }^{-} \mathrm{N}$ giderimi sağlanmış ve buna karşılık $2 \mathrm{mg} / 1 \mathrm{NO}_{2}{ }^{-} \mathrm{N}, 15 \mathrm{mg} / \mathrm{l} \mathrm{N}_{2}$ ve çok az miktarda $(<0.1$ $\mathrm{mg} / \mathrm{l}$ ) ise $\mathrm{NH}_{4}^{+}-\mathrm{N}$ oluşmuştur (Şekil 3.6a). Doz 2 katına çıkarıldığında $\mathrm{Mn}^{0}$ partikülleri içeren yeraltı suyunda $60 \mathrm{dk}$ süre sonunda yaklaşı $\% 41$ civarında $\mathrm{NO}_{3}{ }^{-} \mathrm{N}$ kimyasal denitrifikasyonu sağlanmış ve bu giderime karşıllık ortalama $2.7 \mathrm{mg} / 1 \mathrm{NO}_{2}{ }^{-} \mathrm{N}, 12.3 \mathrm{mg} / 1 \mathrm{~N}_{2}$ ve çok az miktarda (<0.1 mg/l) ise $\mathrm{NH}_{4}{ }^{+}-\mathrm{N}$ oluşmuştur (Şekil 3.6c). Yeraltı suyu örneği doğal bir örnek olduğundan içeriğinde yüksek miktarda katyon ve anyonlar bulunmaktadır. Bu sebeple partikül yüzeyi hızla diğer iyonlar tarafından kaplanmakta ve yüzey aktivasyonu ile kimyasal denitrifikasyon verimi azalmaktadır.

Birleşik yapılan deneyde (US/Mn $\left.{ }^{0}\right) 1 \mathrm{~g} \mathrm{Mn}^{0}$ partikülü kullanıldığında $60 \mathrm{dk}$ süre sonunda yaklaşık \%50 civarında nitrat giderimi sağlanmış ve $0.4 \mathrm{mg} / 1 \mathrm{NO}_{2}^{-}-\mathrm{N}, 20.5 \mathrm{mg} / \mathrm{l} \mathrm{N} \mathrm{N}_{2}$ ve çok az

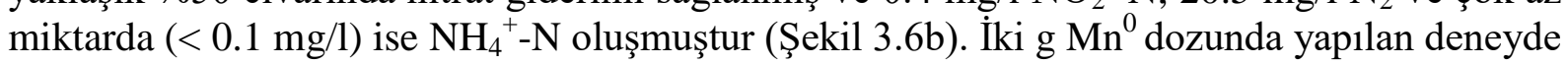
ultrases uygulamasıyla birlikte nitrat kimyasal denitrifikasyonunun ciddi ölçüde arttığ belirlenmiştir. Nitrat giderimi \%93 seviyesine çıkmış ve arıtma sonucunda $0.02 \mathrm{mg} / 1 \mathrm{NO}_{2}{ }^{-} \mathrm{N}$, $38.9 \mathrm{mg} / \mathrm{l} \mathrm{N} \mathrm{N}_{2}$ ve çok az miktarda $(<0.1 \mathrm{mg} / \mathrm{l})$ ise $\mathrm{NH}_{4}{ }^{+}-\mathrm{N}$ elde edilmiştir (Şekil 3.6d). Bu sonuçlara göre, ultrasonik kavitasyon sayesinde $\mathrm{Mn}^{0}$ partikül yüzeyi daha aktif hale geldiğinden nitratın indirgemesi kayda değer ölçüde hızlanmış ve bunun sonucu olarak da ortamda ağırlıklı olarak $\mathrm{N}_{2}$ gazı oluşmuştur. Ultrases mekanik kuvvet etkisi ile partikül yüzeyinde pasif film oluşumu daha az olduğundan nitrat giderim verimi de yüksek elde 
edilmiştir. Yapılan bir çalışmada, yeraltı suyundan nitratın gideriminde magnezyum tek başına kullanıldığında nitrat indirgemesi düşük iken, ultrases gücü ve doz miktarını arttırınca nitratın magnezyumla denitrifikasyonunun ciddi ölçüde arttığı belirlenmiştir (İleri ve ark., 2015).
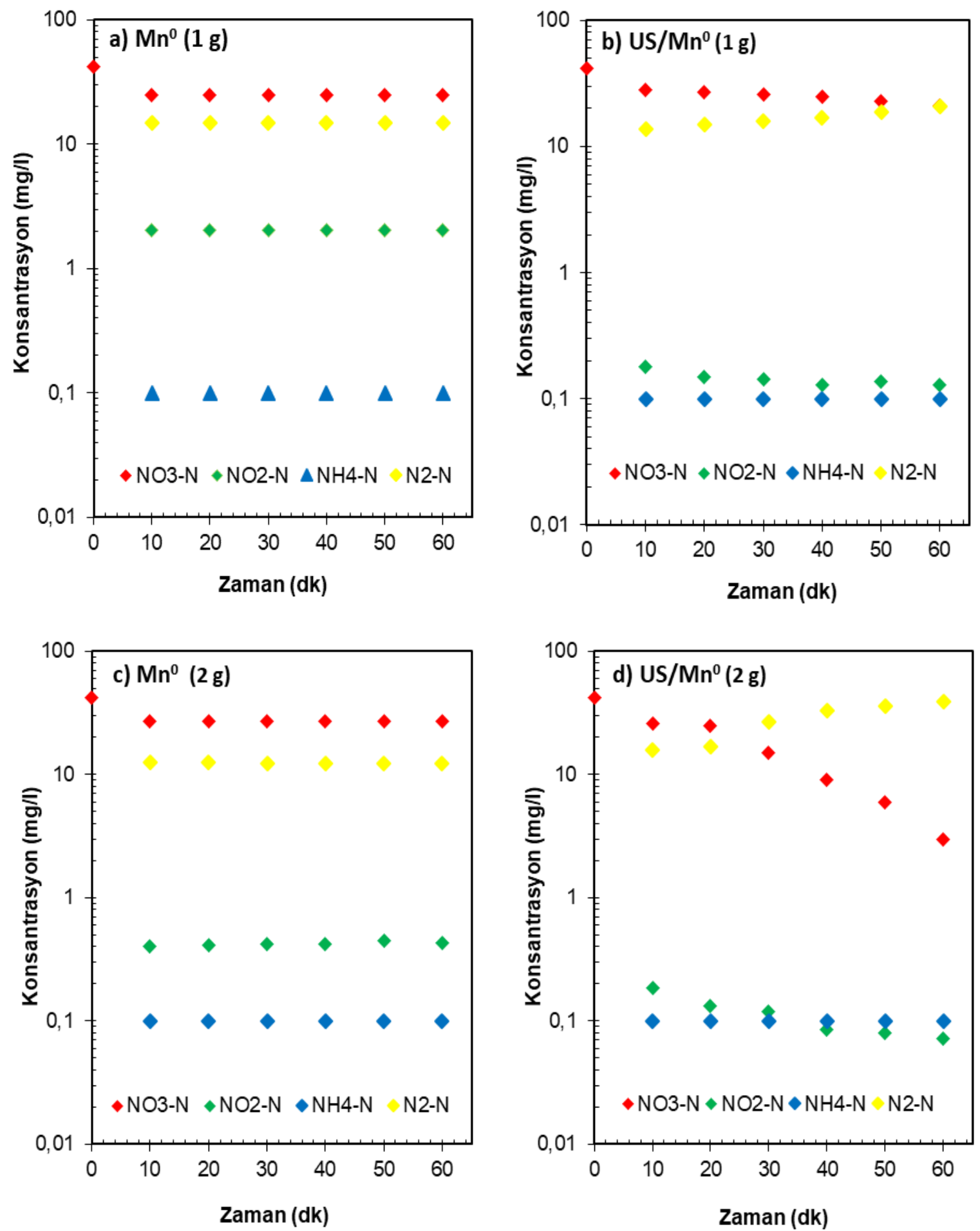

Şekil 3.6. $\mathrm{Mn}^{0}$ ve US/ $\mathrm{Mn}^{0}$ ile yeraltı suyunda bulunan nitratın indirgemesi sonucunda oluşan azotlu bileşiklerin zamana bağlı değişimi $\left(\mathrm{C}_{0}=42 \mathrm{mg} \mathrm{NO}_{3}{ }^{-} \mathrm{N} / \mathrm{l}\right.$; MOPs $\left.=1 \mathrm{~g}\right)$ 


\subsection{Sıfır Değerlikli Mangan İle Nitrat Giderim Reaksiyonunun XRD Analiz Sonucu İle Açıklanması}

Reaksiyon sonrası nitratın su içerisinde kimyasal denitrifikasyonuna bağlı olarak $\mathrm{Mn}^{0}$ partiküllerinin minerolojik yapısında meydana gelen değişiklikler XRD analizi ile tespit edilmiş ve Şekil $3.7 b$ ve c'de gösterilmiştir. Partikül minerolojik yapısında meydana gelen değişiklikleri belirlemek amaciyla $\mathrm{Mn}$, mangan hidroksit $\left(\mathrm{Mn}(\mathrm{OH})_{2}\right)$ ve mangan dioksit $\left(\mathrm{MnO}_{2}\right)$ karşılık gelen pik şiddeti değerleri ölçülmüştür. X-ışını kırınımı (XRD) analizine göre, $\mathrm{Mn}^{0}$ partikülünün çoğunlukla $\mathrm{Mn}$ formunda olduğu görülmektedir (Şekil 3.7a). Nitrat indirgemesinde $\mathrm{Mn}^{0}$ partikülü tek başına kullanıldığında reaksiyon sonunda oksit formlardan $\mathrm{MnO}_{2}$ ve $\mathrm{Mn}(\mathrm{OH})_{2}$ oluşumu tespit edilmiştir (Şekil 3.7b). Nitratın indirgemesi sonucu sıfir yüklü mangan $\mathrm{Mn}^{+2}$ ye yükseltgenerek $\mathrm{Mn}(\mathrm{OH})_{2}$ ile $\mathrm{MnO}_{2}$ katısı şeklinde çöktüğü XRD analizi ile belirlenmiştir. Mangan metalik partiküllerinin suya ilave edildikten hemen sonra oksit formlarının oluşması sonucu partikül yüzeyini kaplayarak reaktif özelliğini kaybettiği anlaşılmaktadır (Eşitlik 10, 11).

$$
\begin{aligned}
& \mathrm{Mn}^{+2}+1 / 2 \mathrm{O}_{2}+2 \mathrm{H}_{2} \mathrm{O} \rightarrow \mathrm{Mn}(\mathrm{OH})_{2(\mathrm{k})}+2 \mathrm{H}^{+} \\
& \mathrm{MnOH}_{2}+\mathrm{H}_{2} \mathrm{O} \rightarrow \mathrm{MnO}_{2(\mathrm{k})}+4 \mathrm{H}^{+}
\end{aligned}
$$

$\mathrm{US} / \mathrm{Mn}^{0}$ uygulaması ile nitratın kimyasal denitrifikasyon kapasitesi ciddi anlamda iyileştirilmiştir. US/ $\mathrm{Mn}^{0}$ birlikte kullanıldığında, $\mathrm{Mn}^{0} / 0 \mathrm{kHz}$ ile pik şiddetleri arasında fark olduğu tespit edilmiştir. Ultrases etkisiyle partikül yüzeyine artan difüzyon hızı ile daha fazla nitrat giderimi sağlandığı ve hızlanan reaksiyon sonucu $\mathrm{Mn}^{0}$ elementi içeriğinin azalmasıyla $\mathrm{MnO}_{2}$ ve $\mathrm{Mn}(\mathrm{OH})_{2}$ oksit formların pik şiddetlerinin arttğı görülmektedir (Şekil 3.7c). Oluşan oksit formların fazla olması $\mathrm{Mn}^{0}$ partikülü ile nitratın daha fazla reaksiyona girdiğini ve indirgendiğini göstermektedir.

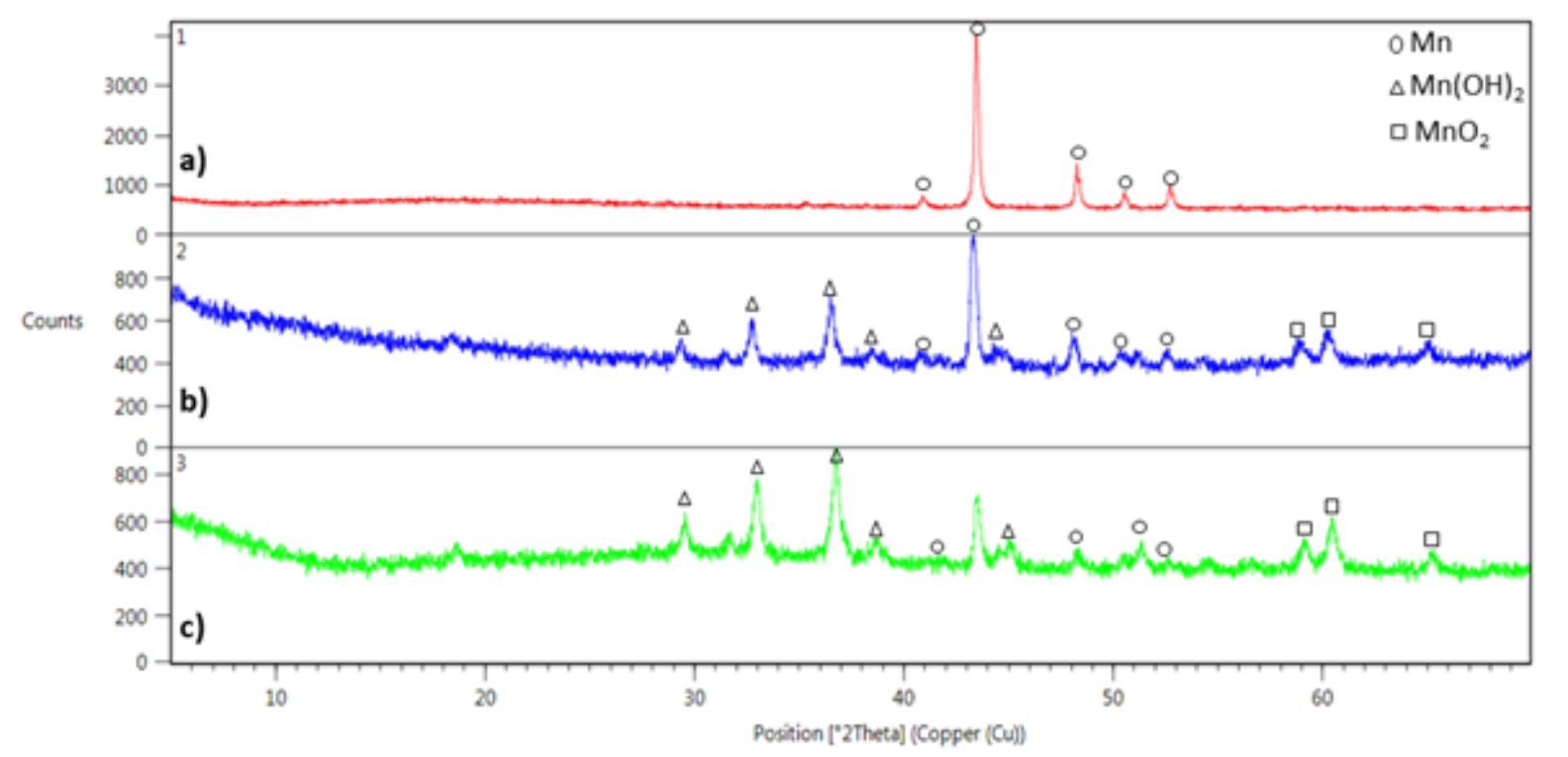

Şekil 3.7. Sifir değerlikli mangan partikülünün reaksiyon öncesi (a) $\mathrm{Mn}^{0}$ ve reaksiyon sonrası b) $\mathrm{Mn}^{0} / 0 \mathrm{kHz}$; c) $\mathrm{Mn}^{0} / 40 \mathrm{kHz}$ XRD sonucu $\left(\mathrm{C}_{0}=50 \mathrm{mg} \mathrm{NO}_{3}{ }^{-} \mathrm{N} / \mathrm{l} ; \mathrm{t}=60 \mathrm{dk}\right)$ 


\section{Sonuç}

Sentetik ve yeraltı suyunda bulunan nitratın indirgenmesinde amonyum veya tercihen azot gazına dönüşümü sağlamak amacıyla sıfır değerlikli mangan $\left(\mathrm{Mn}^{0}\right)$ tekli ve birleşik US/ $\mathrm{Mn}^{0}$ prosesi kullanılmış ve partikül dozu $(0.5-2 \mathrm{~g})$ ile reaksiyon süresi $(0-60 \mathrm{dk})$ parametrelerinin etkisi kesikli testler ile araştırılmıştır. Birleşik $\mathrm{US} / \mathrm{Mn}^{0}$ ile partikül yüzey alanının artması ve çap aralığının azaltılması sağlanarak nitrat indirgenmesi daha kısa sürede ve düşük dozda sağlanmıştır. Birleşik US/ $\mathrm{Mn}^{0}$ uygulaması ile en yüksek giderim verimi $1 \mathrm{~g}$ dozda ve 20 . dk'da elde edilirken; yalnız $\mathrm{Mn}^{0}$ kullanıldığında $2 \mathrm{~g}$ dozda ve 40. dk'da elde edilmiştir. Ultrases kavitasyonu reaksiyon hızını ve difüzyonu arttırdığı için nitrat kimyasal denitrifikasyonun oldukça yüksek olduğu görülmektedir. $\mathrm{Mn}^{0}$ ve US/Mn ${ }^{0}$ proseslerinin nitrat giderimine olan etkisinin daha net açıklanabilmesi için XRD analizi yapılmış ve oluşan oksit formların $\left(\mathrm{MnO}_{2}, \mathrm{Mn}(\mathrm{OH})_{2}\right)$ birleşik US/ $\mathrm{Mn}^{0}$ prosesinde daha fazla olduğu tespit edilmiştir. Oluşan oksit formların fazla olması $\mathrm{Mn}^{0}$ partikülü ile nitratın daha fazla reaksiyona girdiğini ve indirgendiğini göstermektedir. Optimum deneysel şartlar dikkate alınarak, nitrat bakımından zengin bir yeraltı suyunun arıtımında $\mathrm{Mn}^{0}$ ve US/Mn ${ }^{0}$ proseslerinin etkisi araştırılmıştır. Bir ve $2 \mathrm{~g} \mathrm{Mn}^{0}$ dozunda, nitrat giderim verimleri sırasıyla $\mathrm{Mn}^{0}$ partikülü için $\% 40$ ve $\% 41$ iken; birleşik US/Mn ${ }^{0}$ prosesleri için sırasıyla \%51 ve \%93 oranında giderim verimleri elde edilmiştir. Yeraltı suyunda yüksek konsantrasyonda bulunan katyon ve anyon bileşikleri partikül yüzeyini hızla kaplayarak giderim kapasitesinin düşmesine sebep olduğu düşünülmektedir. Sonuç olarak, $\mathrm{Mn}^{0}$ ve $\mathrm{US} \mathrm{Mn}^{0}$ proseslerinin nitratın kimyasal denitrifikasyonunda etkili prosesler olduğu tespit edilmiştir. Ultrases prosesinin $\mathrm{Mn}^{0}$ yüzey aktivitesine etkisinin yüksek olması ile nitrat giderim verimi düşük doz ve kısa sürede elde edilmiştir. Birleşik US/ $\mathrm{Mn}^{0}$ ile ilgili yapılan çalışma literatürde bulunmadığından elde edilen bu sonuçların bundan sonraki atıksu veya yeraltı suyunda bulunan diğer kirleticilerin giderimi konusunda yapılacak çalışmalar için önemli bir referans olacağı düşünülmektedir.

\section{Teșekkür}

Çanakkale Onsekiz Mart Üniversitesi Çevre Mühendisliği Bölümünde yürütülen bu çalışma, TÜBİTAK 2209-A Üniversite Öğrencileri Araştırma Projeleri Destekleme Programı 1919B011602884 numaralı projesi tarafından desteklenmiştir. TÜBİTAK'a desteklerinden dolayı teşekkür ederiz. 


\section{Kaynaklar}

Adewuyi Y.G., 2001. Reviews-sonochemistry: Environmental Science and Engineering Applications. Ind. Eng. Chem. Res., 40: 4681-4715.

Agrawal G.D., Lunkad S.K., Malkhed T., 1999. Diffuse Agricultural Nitrate Pollution of Groundwaters in India. Water Science and Technology, 39 (3): 67-75.

Almasri M.N., 2007. Nitrate Contamination of Groundwater: A Conceptual Management Framework. Environmental Impact Assessment Review, 27 (3): 220-242.

Almasri M.N., Kaluarachchi J.J., 2004. Assessment and Management of Long-term Nitrate Pollution of Groundwater in Agriculture-dominated Watersheds. Journal of Hydrology, 295 (1-4): 225-245.

APHA, 2005. Standard Methods for the Examination of Water and Wastewater. 21st ed. American Public Health Association, Washington, DC, USA.

Archna Sharma S. K., Sobti R.C., 2012. Nitrate Removal from Groundwater: A Review. EJournal of Chemistry, 9 (4): 1667-1675.

Bokare A.D., Cho W., 2008. Zero-valent Aluminum for Oxidative Degradation of Aqueous Organic Pollutants. Environmental Science and Technology, 43 (18): 7130-7135.

Chiu Y.T., Lin C.H., Jechan Lee J., Andrew Lin K.Y., 2019. Reduction of Nitrate to Nitrite in Water by Acid-washed Zero-valent Zinc. Separation Science and Technology.

Choe S., Liljestrand H. M., Khim J., 2004. Nitrate Reduction by Zero-valent Iron under Different pH Regimes. Applied Geochemistry, 19 (3): 335-342.

Crane R.A., Scott T.B., 2012. Nanoscale Zero-valent Iron: Future Prospects for an Emerging Water Treatment Technology. Journal of Hazardous Materials, 211-212: 112-125.

Dada A.O., Adekola F.A., Odebunmi, E.O., 2017. A Novel Zerovalent Manganese for Removal of Copper Ions: Synthesis, Characterization and Adsorption Studies. Applied Water Science, 7 (3): 1409-1427.

Doğanlar D.U., 2006. Effects of Wastewater Irrigation on Groundwater Quality. Dokuz Eylül Üniversitesi, Fen Bilimleri Enstitüsü, İzmir, Türkiye. (Yüksek Lisans Tezi) 
Fargas D. R., 2017. In Situ Groundwater Remediation Treatments: Natural Denitrification Study and Nano Zero-Valent Iron Production. Universitat Politècnica De Catalunya, Natural Resources and Environment Doctorate Programme, İspanya. (Doktora Tezi)

Geiger C.L., Ruiz N.E., Clausen C.A., Reinhart, Quinn J.W., 2002. Ultrasound Pretreatment of Elemental Iron: Kinetic Studies of Dehalogenation Reaction Enhancement and Surface Effects. Water Research, 36 (5): 1342-1350.

Harter T., 2009. Agricultural Impacts on Groundwater Nitrate, Nitrates in Groundwater. Southwest Hydrology Magazine, 8 (4): 1-38.

Hu H.Y., Goto N., Fujie K., 2001. Effect of pH on the Reduction of Nitrite in Water by Metallic Iron. Water Research, 35 (11): 2789-2793.

Hwang Y.H., Kim D.G., Shin H.S., 2011. Mechanism Study of Nitrate Reduction by Nano Zero-valent Iron. Journal of Hazardous Materials, 185, 1513-1521.

İleri B., Ayyıldız O., Apaydın O., 2015a. Ultrasound-assisted Activation of Zero-Valent Magnesium for Nitrate Denitrification: Identification of Reaction by-Products and Pathways. Journal of Hazardous Materials, 292: 1-8.

İleri B., Apaydın O., Ayyıldız O., 2015b. Birleşik Ultrases ve Sıfır Değerlikli Magnezyum ile Nitratın pH Kontrollü Denitrifikasyonu. Sigma Mühendislik ve Fen Bilimleri Dergisi, 33 (4): 489-501.

İleri B., 2016. Ultrases ve Sıfır Yüklü Metal Partikülleri $\left(\mathrm{Al}^{0}\right.$ ve $\left.\mathrm{Mg}^{0}\right)$ ile Nitratın Denitrifikasyonu. Yıldız Teknik Üniversitesi, Fen Bilimleri Enstitüsü, İstanbul, Türkiye. (Doktora Tezi)

Kapoor A., Viraraghavan T., 1997. Nitrate Removal from Drinking Water-Review. Journal of Environmental Engineering, 123 (4): 371-380.

Keeney D., Olson R.A., 1986. Sources of Nitrate to Groundwater, Critical Reviews in Environmental Control, 16 (3): 257-304.

Kumar M., Chakraborty S., 2006. Chemical Denitrification of Water by Zero-valent Magnesium Powder. Journal of Hazardous Materials, 135 (1-3): 112-121. 
Liang F., Fan J., Guo Y., Fan M., Wang J., Yang H., 2008. Reduction of Nitrite by Ultrasound-dispersed Nanoscale Zero-valent Iron Particles. Industrial and Engineering Chemistry Research, 47(22): 8550-8554.

Luk G. K., Au-Yeung W.C., 2002. Experimental Investigation on the Chemical Reduction of Nitrate from Groundwater. Advances Environmental Research, 6 (4): 441-453.

Mahamuni N.N., Adewuyi Y.G., 2009. Advanced Oxidation Processes (AOPs) Involving Ultrasound for Waste Water Treatment: A Review with Emphasis on Cost Estimation. Ultrasonic Sonochemistry, 17 (6): 990-1003.

Mason T.J., Peters D., 2001. Advances in Sonochemistry, Ultrasound in Enviromental Protection, Volume 6, JAI an Imprint of Elsevier Science, England.

Mason T.J., Peters D., 2002. Pratical Sonochemistry, Power Ultrasound Uses and Applications, 2nd Edition, Horwood Publishing Limited, England.

Morais N.L.P.A. De, Brett C.M.A., 2002. Influence of Power Ultrasound on the Corrosion of Aluminium and High Speed Steel. Journal of Applied Electrochemistry, 32: 653-660.

Oğuz T. C., 2015. İçme Suyu Arıtımında Yaygın Olarak Karşılaşılan Su Kalite Problemleri ve Arıtımı İçin Çözüm Önerileri. Uzmanlık Tezi, T.C. Orman ve Su İşleri Bakanlığı, Ankara.

Panda A. P., Rout P., Jena K.K., Alhassan S. M., Kumar S.A., Jha U., Dey R. K., Swain S.K., 2019. Core-Shell Structured Zero-Valent Manganese (ZVM): A Novel Nanoadsorbent for Efficient Removal of As(III) and As(V) from Drinking Water. J. Mater. Chem. A, 2019 (7): 9933-9947.

Patel U., Suresh S., 2006. Dechlorination of Chlorophenol by Magnesium-Silver Bimetallic System. Journal of Colloid and Interface, 299 (1): 249-259.

Polat R., Elçi A., Şimşek C., Gündüz O., 2007. İzmir-Nif Dağ1 Çevresindeki Yeraltı Suyu Nitrat Kirliliği Boyutunun Mevsimsel Değerlendirilmesi. 7. Ulusal Çevre Mühendisliği Kongresi, 24-27 Ekim 2007, İzmir. 
Ramavandi B., Mortazavi S.B., Moussavi G., Khoshgard A., Jahangiri M., 2011. Experimental Investigation of the Chemical Reduction of Nitrate Ion in Aqueous Solution by $\mathrm{Mg} / \mathrm{Cu}$ Bimetallic Particles. Reaction Kinetics Mechanisms and Catalysis, 102 (2): 313-329.

Suziki T., Moribe M., Oyama Y., Niinae M., 2012. Mechanism of Nitrate Reduction by Zerovalent Iron: Equilibrium and kinetic studies. Chem. Eng. J., 183, 271-277.

Tsai Y.J., Chou F.C., Cheng T.C., 2009. Coupled Acidification and Ultrasound with Iron Enhances Nitrate Reduction. Journal of Hazardous Materials, 163 (2-3): 743-747.

TS266, 2005. İnsani Tüketim Amaçlı Sular Hakkında Yönetmelik, Ankara.

Zhu I., Getting T., 2012. A Review of Nitrate Reduction Using Inorganic Materials. Environmental Technology Reviews, 1 (1): 46-58.

Zhang J., Hao Z., Zhang Z., Yang Y., Xua X., 2010. Kinetics of Nitrate Reductive Denitrification by Nanoscale Zero-Valent Iron. Process Safety and Environmental Protection, 88: 439-445. 